\title{
Testosterone Affects Song Modulation during Simulated Territorial Intrusions in Male Black Redstarts (Phoenicurus ochruros)
}

\author{
Beate Apfelbeck ${ }^{1 * 9}$, Sarah Kiefer ${ }^{29}$, Kim G. Mortega ${ }^{2,39}$, Wolfgang Goymann ${ }^{1}$, Silke Kipper ${ }^{2}$ \\ 1 Abteilung für Verhaltensneurobiologie, Max-Planck-Institut für Ornithologie, Seewiesen, Germany, 2 AG Verhaltensbiologie, Institut für Biologie, Freie Universität Berlin, \\ Berlin, Germany, 3 Abteilung für Ornithologie, Universität Konstanz, Konstanz, Germany
}

\begin{abstract}
Although it has been suggested that testosterone plays an important role in resource allocation for competitive behavior, details of the interplay between testosterone, territorial aggression and signal plasticity are largely unknown. Therefore, we investigated if testosterone acts specifically on signals that communicate the motivation or ability of individuals to engage in competitive situations in a natural context. We studied the black redstart, a territorial songbird species, during two different life-cycle stages, the early breeding phase in spring and the non-breeding phase in fall. Male territory holders were implanted with the androgen receptor blocker flutamide (Flut) and the aromatase inhibitor letrozole (Let) to inhibit the action of testosterone and its estrogenic metabolites. Controls received a placebo treatment. Three days after implantation birds were challenged with a simulated territorial intrusion (STI). Song was recorded before, during and after the challenge. In spring, both treatment groups increased the number of elements sung in parts of their song in response to the STI. However, Flut/Let-implanted males reacted to the STI with a decreased maximum acoustic frequency of one song part, while placebo-implanted males did not. Instead, placebo-implanted males sang the atonal part of their song with a broader frequency range. Furthermore, placebo-, but not Flut/Let-implanted males, sang shorter songs with shorter pauses between parts in the STIs. During simulated intrusions in fall, when testosterone levels are naturally low in this species, males of both treatment groups sang similar to Flut/Let-implanted males during breeding. The results suggest that song sung during a territorial encounter is of higher competitive value than song sung in an undisturbed situation and may, therefore, convey information about the motivation or quality of the territory holder. We conclude that testosterone facilitates contextdependent changes in song structures that may be honest signals of male quality in black redstarts.
\end{abstract}

Citation: Apfelbeck B, Kiefer S, Mortega KG, Goymann W, Kipper S (2012) Testosterone Affects Song Modulation during Simulated Territorial Intrusions in Male Black Redstarts (Phoenicurus ochruros). PLoS ONE 7(12): e52009. doi:10.1371/journal.pone.0052009

Editor: Paul A. Bartell, Pennsylvania State University, United States of America

Received August 6, 2012; Accepted November 7, 2012; Published December 17, 2012

Copyright: (c) 2012 Apfelbeck et al. This is an open-access article distributed under the terms of the Creative Commons Attribution License, which permits unrestricted use, distribution, and reproduction in any medium, provided the original author and source are credited.

Funding: The study was kindly funded by the Max-Planck Gesellschaft and the 'Berliner Programm' of the Freie Universität Berlin (research travel grants to S. Kiefer and KGM). Novartis kindly provided the authors with letrozole. The funders had no role in study design, data collection and analysis, decision to publish, or preparation of the manuscript.

Competing Interests: The authors have declared that no competing interests exist.

*E-mail: apfelbeck@orn.mpg.de

9 These authors contributed equally to this work.

\section{Introduction}

Sexually selected signals often serve both to attract a mate and to advertise competitive abilities, for example during territorial disputes (reviewed in [1]). Studying the song of male passerine birds may advance our understanding of the mechanisms underlying the use and coordination of such signals. A range of studies revealed that song characteristics can transfer information about the quality of the singer (reviewed in [2]) such as its immune system [3], age (reviewed in [4]), early experience [5] or motivation to contribute to breeding [6].

In many species males modulate their song in an aggressive context: they might select certain song types matching a rival [7], or produce specific song elements only in situations of high arousal [8]. In addition, birds can change song characteristics such as frequency patterns and trill rate $[9,10]$. Male as well as female listeners respond differentiated to such modulations [11-14]. Song modulations can occur on two domains: on the one hand, birds may change the general output of song (e.g. song rate or amplitude), i.e. measures that potentially every male can vary within broad limits. On the other hand, modulation also occurs in structural song characteristics. Structural characteristics describe, for example, song repertoire characteristics [15] or song parts that are challenging to sing, such as rapid broadband trills (reviewed in [16]), specific song trills [17] or consistent syllables [18]. Structural song patterns have been classified as 'index signals' that honestly communicate a physical trait related to male quality [19]. Only very few studies have revealed a capability of individuals to modulate such physically constrained signals within narrow limits $[9,10,20,21]$. Thus, from a functional point of view, index signals such as structural song parameters should play an important role in the communication of competitive ability.

The steroid hormone testosterone plays an important role in the regulation of adult singing and territorial behaviors and the associated vocalizations during breeding are facilitated by testosterone in a wide range of male vertebrates (reviewed in [22], [23]). Therefore, it has been suggested that testosterone might play an important role in resource allocation for competitive behavior 
during reproduction (reviewed in [24]). From this point of view, testosterone should act specifically on signals that communicate the motivation or ability of individuals to engage in competitive situations and is, therefore, expected to be involved in contextdependent adjustment of such signals. However, details of the interplay between hormones, territorial aggression and signal plasticity in a natural context are largely unknown.

Manipulations of testosterone levels may alter song output (measured, for example, as song rate or duration; e.g. [25-29]). Whether testosterone also affects structural song parameters is less clear. In barn swallows (Hirundo rustica), the duration and pulse rate of the harsh 'rattle' element correlated moderately with absolute testosterone levels [30]. Manipulation studies suggested that zebra finches (Taeniopygia guttata) treated with testosterone decreased the fundamental frequency of harmonic stacks in their song [31]. Other correlational and experimental studies with testosterone treatment failed to find effects on structural song parameters $[29,32,33]$. Studies that implant birds with testosterone may be problematic, because especially immediately after implantation testosterone may circulate in pharmacological doses [34,35]. It is thus questionable whether manipulations exclusively within the physiological range of testosterone would reveal similar results. Treatments inhibiting the action of testosterone or its major metabolite estradiol by blocking the androgen receptor and/or the conversion to estradiol avoid such pharmacological effects (but can only inhibit, not enhance effects of steroid hormones). The - so far - only study in which the androgenic and estrogenic pathways of testosterone action were blocked failed to find effects on structural song parameters in great tits (Parus major, [36]). Thus, to the best of our knowledge, an effect of physiological changes in testosterone on structural measures of song has not been demonstrated so far.

Song plasticity and its potentially underlying hormonal mechanisms may be studied in different contexts, such as during spontaneous singing or singing during a territorial challenge because the song used (output and structure), the information transmitted (e.g. quality and/or competitive ability) and the receiver and/or audience (other males and/or females) may differ in these contexts. Thus, depending on context, song may be facilitated by sex steroids or not. Furthermore, several songbird species also sing outside the breeding season, providing an additional contextual variable. Song characteristics (of spontaneous song) differ between the breeding - and non-breeding season: For example, some species produce more repetitive elements [15,37-39], longer songs [40] and more stereotypic song [37] in spring than in fall. Comparisons between breeding and nonbreeding song were so far restricted to spontaneously produced song. Whether changes in song during a territorial challenge also differ between seasons has not been studied yet. Such a difference should be expected from a functional point of view, since fall territories are not of immediate importance for reproduction. Those seasonal differences in song might well be mediated by testosterone levels, because in most songbird species testosterone levels are low during non-breeding [41-44]. It remains open, however, whether and how testosterone is involved in contextdependent song plasticity during the non-breeding season (e.g. [45]). In song sparrows, for example, testosterone also regulates territorial behaviour during the non-breeding season, presumably through steroids of non-gonadal origin that are then metabolized to testosterone and estradiol directly in the brain [46].

In this study, we investigated the role of testosterone in regulating spontaneous song and song in an aggressive context in free-living male black redstarts (Phoenicurus ochruros). The species is well-suited to study this topic as there is evidence that song structures may contain information about the competitive ability or motivation [47]. Black redstarts show delayed song maturation, i.e. adult and yearling males differ in structural song parameters [47] such as the duration of song parts and number of elements or frequential song patterns, as well as in visual traits (delayed plumage maturation) [48]. These age-differences are also reflected in simulated territorial intrusions: adult and yearling males respond differentially to playbacks of the two age classes [47]. Despite this delayed maturation, adults as well as one year olds reproduce, but adult males usually occupy higher quality habitats and have a higher reproductive success [49]. Although this has not yet been studied, it seems plausible to assume that behavioral and morphological age-differences may be accompanied by different hormonal profiles.

Furthermore, black redstarts not only defend territories in spring after having returned from their wintering grounds, but also in fall, just after molt and before migration [50]. During the territorial phase in fall they have low testosterone levels [51].

Against this background, we tested the role of testosterone in the modulation of song characteristics in this species. We did so by implanting birds with an androgen receptor blocker (flutamide) and an aromatase inhibitor (letrozole) which inhibits the conversion of testosterone to estradiol, as testosterone can modulate behavior either directly by binding to androgen receptors or indirectly by conversion to estradiol and binding to estrogen

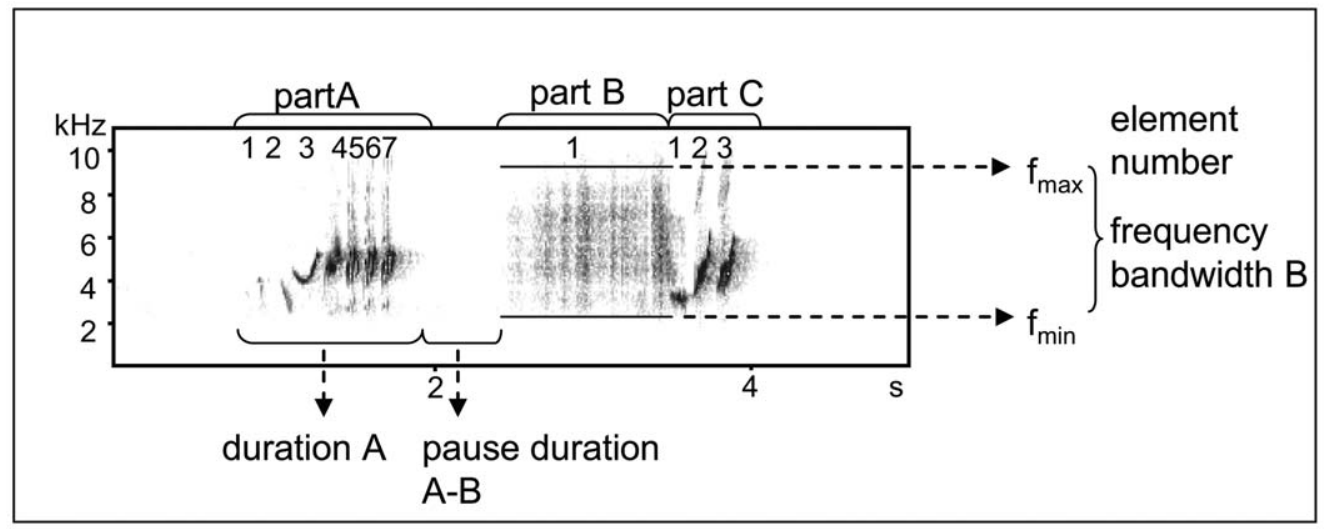

Figure 1. A song of a black redstart illustrating the acoustic measures analyzed (Spectrogram: Avisoft-SASLab Pro, sample rate 22, $050 \mathrm{~Hz}$, FFT = 256 points, Hamming-Window, Overlap: 50\%). doi:10.1371/journal.pone.0052009.g001 


\section{A) breeding season (spring)}

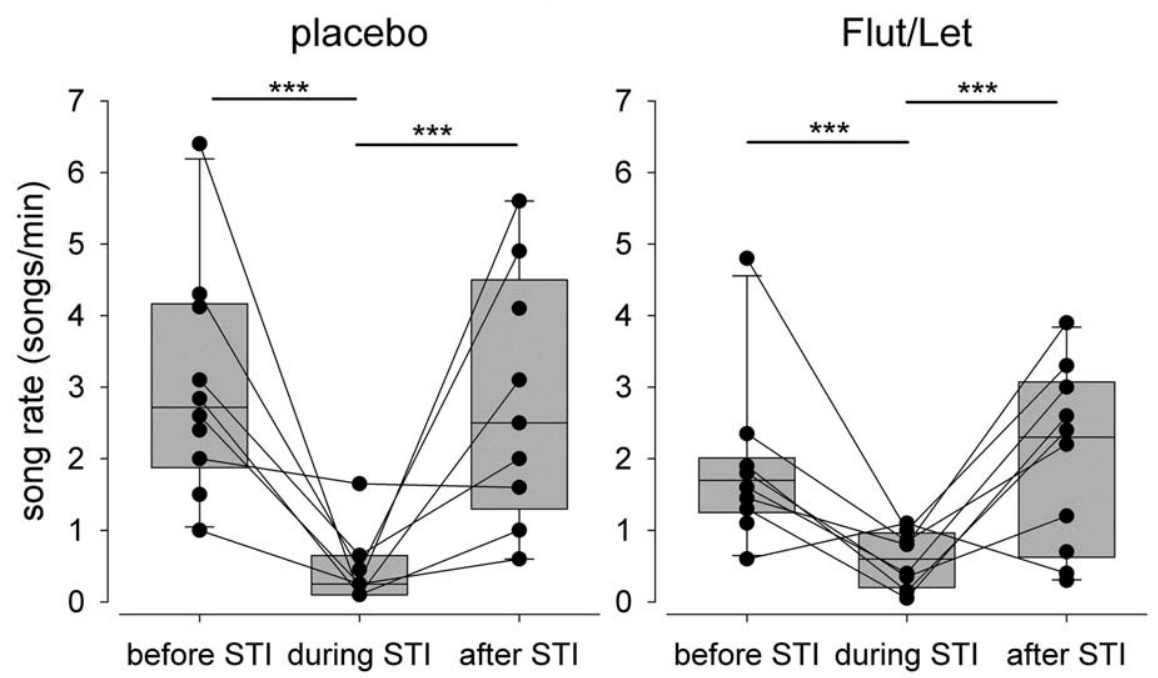

B) nonbreeding season (fall)

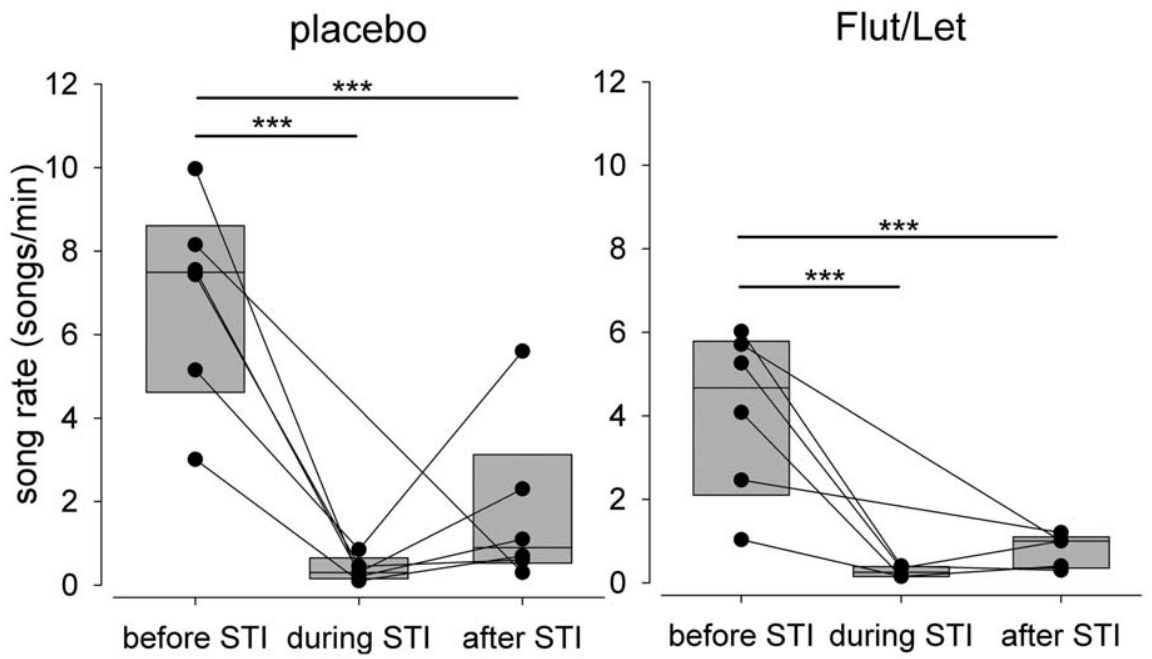

Figure 2. Song rate before, during and after the STI. Depicted separately for males treated with flutamide and letrozole ('Flut/Let') and placebo treated males ('placebo') in A) spring $(n=10$ per group) and $B)$ in fall $(n=6$ per group). Each circle represents one individual male and measurements of the same male are connected by a line. Asterisks indicate significance $\left.{ }^{* * *} p<0.001\right)$ and are according to a priori set contrasts (before vs. STI and before vs. after the STI). Mind the different scales in A and B. doi:10.1371/journal.pone.0052009.g002

receptors [52]. As controls we used birds treated with placebo implants. After implantation, we first recorded the spontaneous song of territorial males in an undisturbed context and then conducted a playback experiment simulating a territorial intrusion (STI) by a foreign male. This procedure was conducted in spring during the early breeding season, and again in fall during nonbreeding, using a different set of birds.

The aim of our study was threefold. First, we wanted to investigate whether black redstarts change structural song parameters in an aggressive context, i.e. whether song parameters differ between a non-challenged context before the STI and during/ after the STI. Based on prior studies on black redstart song and in particular on a playback-study on song and age ( [47], see above) we expected to find changes in song output measures and structural song characteristics. Index signals that honestly communicate a physical trait related to male quality [19] are good candidates here. Thus, we expected those structural song parameters to change in the agonistic context that have been shown to be characteristic for adult males̀ song, that is the number of song elements and the frequency-range of song parts [47]. Specifically we would expect focal males to sing longer song parts with trills, higher frequencies and/or with broader frequency bandwidth during a territorial encounter than in an undisturbed situation.

Second, by blocking the actions of testosterone, we attempted to determine the role of this hormone in context-dependent vocal plasticity. If testosterone is playing a key role in the resource allocation for competitive behavior (e.g. [53]) during the breeding season in spring, we would expect flutamide/letrozole-treated males (thereafter termed Flut/Let males) to invest less in those behaviors and song patterns that are relevant in such situations than placebo-males. Thus, changes in song during territorial encounters (see above) should be less pronounced or absent in Flut/Let males in contrast to placebo treated males. 
Table 1. Linear mixed model results for the effects of context and Flut/Let-treatment on song output and structure in spring.

\begin{tabular}{|c|c|c|c|c|c|}
\hline \multirow[t]{2}{*}{ element } & \multirow[t]{2}{*}{ treatment } & \multirow[t]{2}{*}{ context } & \multirow[t]{2}{*}{ interaction } & \multicolumn{2}{|c|}{ Cohens d [95\% Cl] } \\
\hline & & & & placebo & Flut/Let \\
\hline \multirow[t]{2}{*}{ song rate } & $F_{1,18}=2.3$ & $F_{2,30}=23.6$ & $F_{2,30}=1.3$ & 2.0 & 1.4 \\
\hline & $p=0.1$ & $p<0.0001$ & $p=0.3$ & {$[0.8,3.2]$} & {$[0.4,2.5]$} \\
\hline \multirow[t]{2}{*}{ song duration } & $F_{1,18}=0.2$ & $F_{2,30}=6.7$ & $\mathbf{F}_{2,30}=\mathbf{3 . 8}$ & 1.5 & 0.1 \\
\hline & $p=0.6$ & $p=0.004$ & $p=0.03$ & {$[0.3,2.5]$} & {$[-0.9,1.0]$} \\
\hline \multirow[t]{2}{*}{ duration $\mathrm{A}$} & $F_{1,18}=0.7$ & $F_{2,30}=2.3$ & $F_{2,30}=1.4$ & 0.2 & -1.0 \\
\hline & $p=0.4$ & $p=0.1$ & $p=0.3$ & {$[-0.7,1.2]$} & {$[-2.0,0.01]$} \\
\hline \multirow[t]{2}{*}{ duration $B$} & $F_{1,18}=0.2$ & $F_{2,30}=2.0$ & $F_{2,30}=0.4$ & -0.3 & -0.4 \\
\hline & $p=0.6$ & $p=0.2$ & $p=0.6$ & {$[-1.3,0.7]$} & {$[-1.4,0.5]$} \\
\hline \multirow[t]{2}{*}{ duration $\mathrm{C}$} & $F_{1,18}=0.4$ & $F_{2,30}=0.9$ & $F_{2,30}=0.2$ & 0.7 & -0.1 \\
\hline & $p=0.6$ & $p=0.4$ & $\mathrm{p}=0.8$ & {$[-0.3,1.7]$} & {$[-1.1,0.8]$} \\
\hline \multirow[t]{2}{*}{ duration pause $A-B$} & $F_{1,18}=1.2$ & $F_{2,30}=7.6$ & $F_{2,30}=1.0$ & 1.2 & 0.6 \\
\hline & $p=0.3$ & $p=0.002$ & $p=0.4$ & {$[0.1,2.2]$} & {$[-0.4,1.5]$} \\
\hline \multirow[t]{2}{*}{ no. of elements in A } & $F_{1,18}=0.6$ & $\mathbf{F}_{2,30}=\mathbf{2 3 . 1}$ & $F_{2,30}=1.1$ & -2.6 & -1.7 \\
\hline & $p=0.6$ & $p<0.0001$ & $p=0.4$ & {$[-3.9,-1.3]$} & {$[-2.8,-0.6]$} \\
\hline \multirow[t]{2}{*}{ no. of elements in C } & $F_{1,18}=0.04$ & $F_{2,30}=\mathbf{1 2 . 2}$ & $F_{2,30}=0.9$ & -1.9 & -0.8 \\
\hline & $\mathrm{p}=0.8$ & $p<0.0001$ & $p=0.4$ & {$[-3.0,-0.7]$} & {$[-1.8,0.2]$} \\
\hline \multirow[t]{2}{*}{ freq bandwidth $A$} & $F_{1,18}=1.5$ & $F_{2,30}=1.1$ & $\mathrm{~F} 2,30=2.1$ & 0.01 & 0.7 \\
\hline & $p=0.2$ & $p=0.4$ & $p=0.1$ & {$[-1.0,1.0]$} & {$[-0.3,1.6]$} \\
\hline \multirow[t]{2}{*}{ max frequency $A$} & $F_{1,18}=1.4$ & $\mathbf{F}_{2,30}=\mathbf{3 . 9}$ & $\mathbf{F}_{2,30}=\mathbf{5 . 1}$ & -0.1 & 1.4 \\
\hline & $p=0.3$ & $p=0.03$ & $p=0.01$ & {$[-1.0,0.9]$} & {$[0.3,2.4]$} \\
\hline \multirow[t]{2}{*}{ freq bandwidth $B$} & $F_{1,18}=3.7$ & $\mathbf{F}_{2,30}=\mathbf{4 . 4}$ & $\mathbf{F}_{2,30}=\mathbf{5 . 4}$ & -1.4 & -0.1 \\
\hline & $p=0.07$ & $p=0.02$ & $p=0.009$ & {$[-2.4,-0.3]$} & {$[-1.0,0.9]$} \\
\hline \multirow[t]{2}{*}{ max frequency B } & $\mathbf{F}_{1,18}=\mathbf{6 . 6}$ & $\mathbf{F}_{2,30}=\mathbf{3 . 6}$ & $F_{2,30}=2.0$ & -1.0 & -0.4 \\
\hline & $p=0.02$ & $p=0.04$ & $p=0.2$ & {$[-2.1,0.0]$} & {$[-1.3,0.6]$} \\
\hline \multirow[t]{2}{*}{ freq bandwidth C } & $F_{1,18}=0.1$ & $F_{2,30}=0.9$ & $F_{2,30}=0.09$ & -0.2 & 0.02 \\
\hline & $p=0.7$ & $p=0.4$ & $p=0.9$ & {$[-1.2,0.8]$} & {$[-0.9,1.0]$} \\
\hline \multirow[t]{2}{*}{$\max$ frequency $C$} & $F_{1,18}=0.2$ & $F_{2,30}=2.1$ & $F_{2,30}=0.2$ & 0.1 & 0.2 \\
\hline & $p=0.7$ & $p=0.1$ & $\mathrm{p}=0.8$ & {$[-0.9,1.0]$} & {$[-0.7,1.2]$} \\
\hline
\end{tabular}

Context is a within-subjects factor with three levels: before STI (spontaneously sung songs), during STI (playback and decoy present) and after STI (directly after removal of playback and decoy). Treatment is a between-subjects factor with two levels: placebo-implanted vs. blocker-implanted males. To control for repeated measures the ID of each territory owner was included as random intercept. Significant results are highlighted in bold.

doi:10.1371/journal.pone.0052009.t001

Thirdly, because testosterone levels are low in fall [51] males should not change song parameters in an aggressive context in fall and the treatment with flutamide and letrozole should have no effect on song. We therefore, compared song behavior in an undisturbed and an agonistic context in fall again between Flut/ Let males and placebo males. We predicted that in fall Flut/Letand placebo-implanted males should not differ in their vocal response to a simulated territorial intrusion.

\section{Materials and Methods}

\section{Ethics Statement}

All experimental procedures were approved by the Committee on the Ethics of Animal Experiments of the governmental authorities of Upper Bavaria (Permit Number: Az. 55.2-1-542531-151-08). All surgery was performed under local carprofen anesthesia, and all efforts were made to minimize suffering.

\section{Study Site and Subjects}

Adult territorial male black redstarts were caught during spring (9-27 April 2009) and fall (22 September - 7 October 2009) in Upper Bavaria, Germany (N $\left.47^{\circ}, \mathrm{E} 11^{\circ}\right)$ with mealworm-baited ground traps. To avoid potential age-related differences in song and hormonal profile (see Introduction) we restricted our study to males being 2 yrs or older. Birds were lured to the traps by broadcasting playbacks of the species' song of short duration $(<2 \mathrm{~min})$. We remotely muted the loudspeaker as soon as the territory owner approached the traps. Conspecific playback does not influence testosterone levels in territorial male black redstarts [51]. Males were implanted with either one placebo pellet (spring: $\mathrm{n}=10$, fall: $\mathrm{n}=6$ ) or two time release pellets (spring: $\mathrm{n}=10$, fall: $\mathrm{n}=6,21$ day release: $1.5 \mathrm{mg}$ per pellet; release rate $71 \mu \mathrm{g} /$ day; $\varnothing=3.2 \mathrm{~mm}$, Innovative Research of America, Sarasota, FL) containing the androgen receptor blocker flutamide (SigmaAldrich F-9397) and the aromatase inhibitor letrozole (Novartis; [54]), respectively. Each male was implanted only once, either in spring or fall. Implants were inserted subcutaneously on the back 

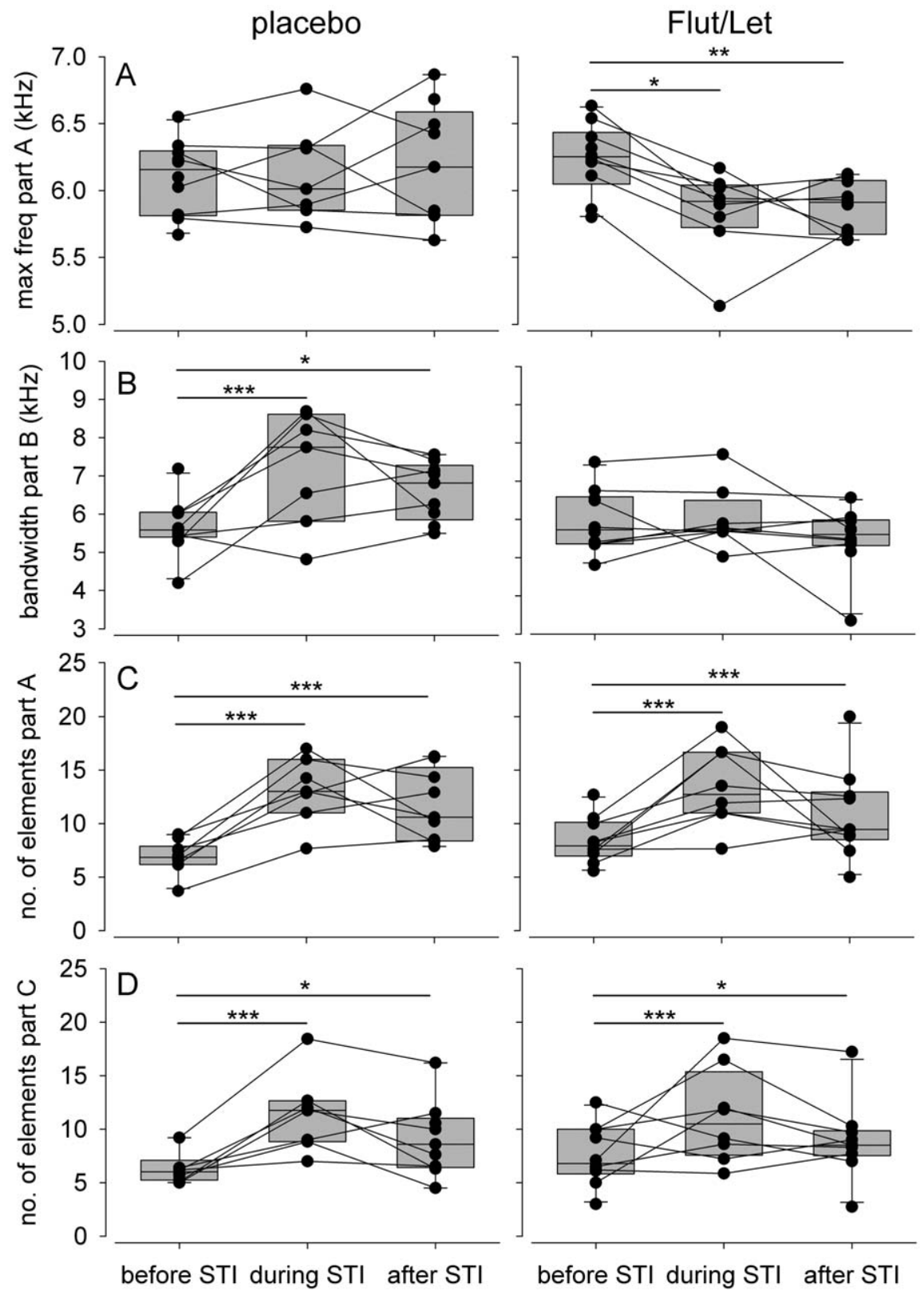

Figure 3. Structural song measures before, during and after the STI. Depicted separately for males treated with flutamide and letrozole ('Flut/Let', $\mathrm{n}=10$ ) and placebo treated males ('placebo', $\mathrm{n}=10$ ) in spring. Each circle represents one individual male and measurements of the same male are connected by a line. Asterisks indicate significance $\left({ }^{*} p<0.05,{ }^{*} p<0.01,{ }^{* *} p<0.001\right)$ and are according to a priori set contrasts (before vs. STI and before vs. after the STI).

doi:10.1371/journal.pone.0052009.g003

between the wings through a small incision in the skin that was sealed with tissue glue afterwards (Nexaband; World Precision Instruments).

Control and experimental groups did not differ significantly in body mass (spring: $\mathrm{t}=1.52, \mathrm{df}=17.9, \mathrm{p}=0.15$, fall: $\mathrm{W}=34.5$, $\mathrm{n}=16, \mathrm{p}=0.8$ ), length of the right tarsus (spring: $\mathrm{t}=-0.25$, $\mathrm{df}=12.5, \mathrm{p}=0.8$, fall: $\mathrm{W}=44, \mathrm{n}=16, \mathrm{p}$-value $=0.2)$, length of the right wing $(\mathrm{t}=0.25, \mathrm{df}=14.2, \mathrm{p}=0.8$, fall: $\mathrm{W}=41, \mathrm{n}=16, \mathrm{p}-$ value $=0.4)$ and cloacal protuberance $(\mathrm{CP})$ volume (spring: $\mathrm{t}=-0.17, \mathrm{df}=13.1, \mathrm{p}=0.9)$, which was estimated by calculating the volume of a cylinder $\left[\mathrm{V}=\pi^{*}(\mathrm{CP}\right.$ width $/ 2) 2 * \mathrm{CP}$ height $]$.

Each male was banded with a numbered aluminum ring (Vogelwarte Radolfzell) and a unique combination of three color rings for individual recognition. Measuring, ringing and implanting the birds took no longer than 25 min after which the males were released onto their territories.

\section{Experimental Design}

Simulated territorial intrusions were conducted three days after implantation. All experiments were conducted between 8:00 and 12:00 h. For the playback we used spontaneous songs from 20 adult male black redstarts recorded in spring 2009 and from 12 adult males recorded in fall 2009 with the same equipment as reported below. For each target male we selected a playback that was recorded at least $10 \mathrm{~km}$ away from the study area. This distance was sufficient to avoid that target birds might know the 

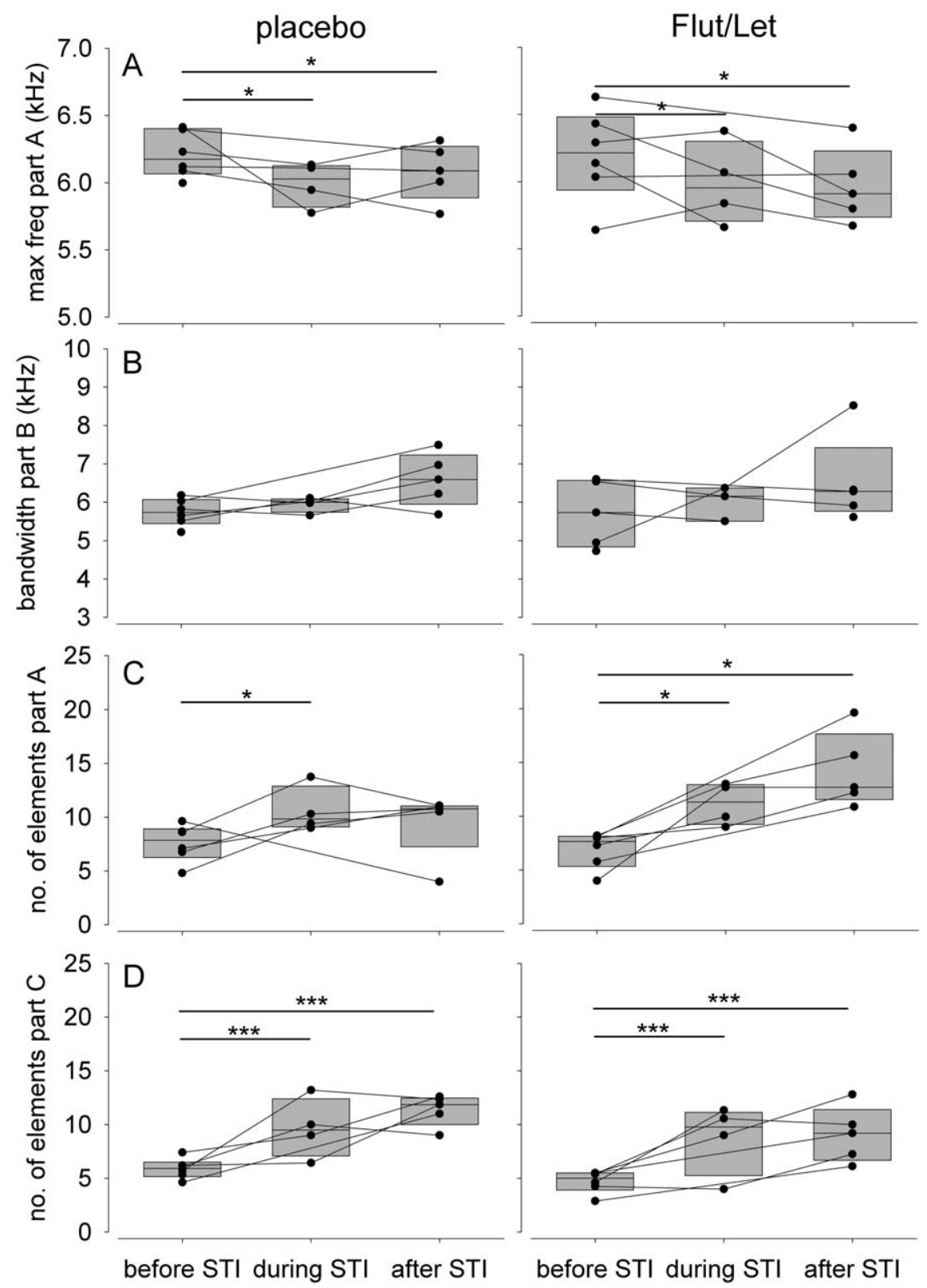

Figure 4. Structural song measures before, during and after the STI. Depicted separately for males treated with flutamide and letrozole ('Flut/Let', $n=6$ ) and placebo treated males ('placebo', $n=6$ ) in fall. Each circle represents one individual male and measurements of the same male are connected by a line. Asterisks indicate significance $\left({ }^{*} p<0.05,{ }^{* * *} p<0.001\right)$ and are according to a priori set contrasts (before vs. STI and before vs. after the STI).

doi:10.1371/journal.pone.0052009.g004

stimulus birds. Playbacks were put together using Avisoft-SASLab Pro software, version 4.51 (Raimund Specht, Berlin, Germany). Each playback consisted of 20 songs recorded from one male. Songs were filtered ( $1 \mathrm{kHz}$ high-pass filter) and amplitude was normalized to $75 \%$. A playback consisted of each of two different song types (X and $\mathrm{Y}$ ) played back in a XXYYXXYYXX sequence, with $\mathrm{X}$ and $\mathrm{Y}$ in 10 different versions (i.e. different exemplars of the same type). Songs were divided by pauses of $4.5 \mathrm{~s}$. By repeating each sequence six times the playback had a duration of 20 minutes in total. This design resembled the organization of natural song in this species.

We presented each of the playbacks twice: once to a Flut/Let bird and once to a control bird, thereby alternating the presentation order between the two groups. These pairs of groups were tested in close temporal proximity in order to rule out e.g. seasonal or male status effects. In addition, by this paired design we were able to control for effects of different source bird song. The simulated territorial intrusion (STI) experiments were performed by placing a stuffed decoy (male in full adult plumage protected by an inconspicuous cage, three different decoys used) into the center of the respective territories. A remote-controlled loudspeaker (Foxpro Scorpion, digital game caller, FOXPRO Inc. Lewistown, USA) was put underneath the decoy to play back the territorial song of a potential rival at a sound pressure level of $65 \mathrm{~dB}$ SPL at $1 \mathrm{~m}$ (as measured with a CEL 573.B1 Sound Level Analyzer). We only started an experiment when a male was 
Table 2. Linear mixed model results for the effects of context and Flut/Let treatment on song output and structure in fall.

\begin{tabular}{|c|c|c|c|c|c|}
\hline \multirow[t]{2}{*}{ element } & \multirow[t]{2}{*}{ treatment } & \multirow[t]{2}{*}{ context } & \multirow[t]{2}{*}{ interaction } & \multicolumn{2}{|c|}{ Cohens d $[95 \% \mathrm{Cl}]$} \\
\hline & & & & placebo & Flut/Let \\
\hline \multirow[t]{2}{*}{ song rate } & $F_{1,10}=3.0$ & $F_{2,18}=\mathbf{4 3 . 1}$ & & 2.3 & 2.4 \\
\hline & $p=0.1$ & $p<0.0001$ & & {$[0.8,3.8]$} & {$[0.8,3.9]$} \\
\hline \multirow[t]{2}{*}{ song duration } & $F_{1,10}=0.02$ & $F_{2,18}=2.1$ & & 0.8 & 0.1 \\
\hline & $\mathrm{p}=0.9$ & $p=0.1$ & & {$[-0.4,2.9]$} & {$[-1.0,1.2]$} \\
\hline \multirow[t]{2}{*}{ duration $\mathrm{A}$} & $F_{1,10}=4.3$ & $F_{2,18}=3.2$ & & 0.3 & -1.3 \\
\hline & $p=0.06$ & $p=0.06$ & & {$[-0.8,1.5]$} & {$[-1.3,1.0]$} \\
\hline \multirow[t]{2}{*}{ duration $B$} & $F_{1,10}=0.01$ & $F_{2,18}=0.7$ & & 0.7 & 0.05 \\
\hline & $p=0.9$ & $p=0.5$ & & {$[-0.5,1.8]$} & {$[-1.1,1.2]$} \\
\hline \multirow[t]{2}{*}{ duration C } & $F_{1,10}=2.2$ & $F_{2,18}=3.4$ & & -0.1 & -0.7 \\
\hline & $p=0.2$ & $p=0.06$ & & {$[-1.2,1.0]$} & {$[-1.9,0.5]$} \\
\hline \multirow[t]{2}{*}{ duration pause $A-B$} & $F_{1,10}=0.4$ & $F_{2,18}=0.1$ & & -0.2 & 0.6 \\
\hline & $p=0.5$ & $p=0.9$ & & {$[-1.3,1.0]$} & {$[-0.6,1.7]$} \\
\hline \multirow[t]{2}{*}{ no. of elements in A } & $F_{1,10}=2.4$ & $F_{2,14}=11.9$ & $F_{2,14}=3.8$ & -1.6 & -2.6 \\
\hline & $p=0.2$ & $p<0.001$ & $p=0.05$ & {$[-3.0,-0.1]$} & {$[-4.1,-0.9]$} \\
\hline \multirow[t]{2}{*}{ no. of elements in C } & $F_{1,10}=0.2$ & $\mathbf{F}_{2,16}=\mathbf{2 6 . 1}$ & & -4.2 & -2.3 \\
\hline & $p=0.2$ & $p<0.0001$ & & {$[-6.4,-1.9]$} & {$[-3.7,-0.7]$} \\
\hline \multirow[t]{2}{*}{ freq bandwidth $A$} & $F_{1,10}=0.2$ & $F_{2,16}=2.0$ & & 0.6 & 2.1 \\
\hline & $p=0.7$ & $p=0.2$ & & {$[-0.6,1.8]$} & {$[0.5,3.6]$} \\
\hline \multirow[t]{3}{*}{ max frequency $A$} & $F_{1,10}=0.08$ & $\mathbf{F}_{2,16}=\mathbf{3 . 9}$ & & 0.7 & 0.9 \\
\hline & $p=0.8$ & $p=0.04$ & & {$[-0.6,1.9]$} & {$[-0.3,2.1]$} \\
\hline & & & & \multicolumn{2}{|c|}{ combined: $1.0[0.1,0.9]$} \\
\hline \multirow[t]{2}{*}{ freq bandwidth B } & $F_{1,10}=0.7$ & $F_{2,13}=3.2$ & & -1.6 & -0.6 \\
\hline & $p=0.4$ & $p=0.08$ & & {$[-3.0,-0.2]$} & {$[-1.8,0.6]$} \\
\hline \multirow[t]{2}{*}{ max frequency $B$} & $F_{1,10}=1.5$ & $\mathbf{F}_{2,13}=\mathbf{5 . 0}$ & & -1.9 & -0.8 \\
\hline & $p=0.2$ & $p=0.02$ & & {$[-3.3,-0.4]$} & {$[-2.0,0.5]$} \\
\hline \multirow[t]{2}{*}{ freq bandwidth $C$} & $F_{1,10}=0.03$ & $F_{2,16}=3.6$ & & 1.0 & 0.5 \\
\hline & $p=0.9$ & $p=0.05$ & & {$[-0.3,2.3]$} & {$[-0.7,1.6]$} \\
\hline \multirow[t]{2}{*}{$\max$ frequency $C$} & $F_{1,10}=0.1$ & $F_{2,16}=2.2$ & & 0.8 & 0.3 \\
\hline & $p=0.7$ & $p=0.1$ & & {$[-0.5,2.9]$} & {$[-0.9,1.4]$} \\
\hline
\end{tabular}

Context is a within-subjects factor with three levels: before STI (spontaneously produced songs), during STI (playback and decoy present) and after STI (directly after removal of playback and decoy). Treatment is a between-subjects factor with two levels: placebo-implanted versus blocker-implanted males. Significant results are highlighted in bold.

doi:10.1371/journal.pone.0052009.t002

singing. The song was recorded 10 min prior to the start of the STI, during the 20 min STI and 10 min after the STI with a Sennheiser directional microphone (ME66/K6) connected to a Marantz solid state recorder PMD 660 (sampling frequency: $44.1 \mathrm{kHz}$; resolution: $16 \mathrm{bit})$.

\section{Data Analysis}

The song was analyzed using Avisoft-SASLab Pro software, version 4.51. Recordings were visualized in spectrograms (settings: sample rate $22,050 \mathrm{~Hz}, \mathrm{FFT}=256$ points, Hamming-window, overlap: $50 \%$ ). We determined the number of songs by visual inspection and selected songs of sufficient quality (low background noise) for further sound analysis. Each song of black redstarts can be divided into three distinct parts (part A, B and C, see Fig. 1 and e.g. [47]) with a pause of varying duration between part $A$ and $B$. We measured the duration of parts $\mathrm{A}, \mathrm{B}$ and $\mathrm{C}$, the total song and the duration of pauses between A and B (Fig. 1). We counted the number of elements of part A and $\mathrm{G}$ (mean of max. 20 song renditions). We also determined the frequency bandwidth and the maximum frequency of part $\mathrm{A}, \mathrm{B}$ and $\mathrm{C}$ using the automatic parameter measurement function (threshold $-20 \mathrm{~dB}$ ) in Avisoft (mean of max. 10 renditions of high-quality songs).

Data were analyzed with $\mathrm{R}$ version 2.9.1 [55]. Song before, during, and after the STI was analyzed using general linear mixed models with bird identity as a random effect to control for repeated measures. We analyzed whether the dependent variables (number of songs, song duration, duration of part A, B, C and the pause between part $\mathrm{A}$ and $\mathrm{B}$, the number of elements in part $\mathrm{A}$ and $\mathrm{C}$ and maximum frequency and bandwidth of all parts) were influenced by the Flut/Let treatment, the context (testing phase of the STI) and their interaction. In all cases, dependent variables where transformed if assumptions of normality and/or equality of variances were not met. Significance was accepted at $\alpha \leq 0.05$ (two-tailed). 


\section{Results}

\section{Song in Spring}

Males sang significantly fewer songs during the STI than when singing spontaneously before and after the STI (Fig. 2a, Table 1). Song duration significantly changed in placebo-implanted males, with songs during the STI being shorter than before or after the STI. In Flut/Let-males, song duration remained constant before, during and after the STI (Table 1). The shortening of the song in placebo-implanted males was mainly due to a significantly shorter pause between song part A and B (Table 1), because the durations of the three song parts (A, B and $\mathrm{G}$ ) did not differ significantly before, during and after the STI (Table 1).

Both placebo-implanted and Flut/Let-males sang significantly more elements in song parts A and C during and after the STI than before the STI (Table 1, Figs. 3c, d). This element increase resulted from an increase in the number of elements of the trilled phrases of part A or C, respectively (Fig. 1). By definition, part B did not change with respect to this measure because it consisted of one element only (Fig. 1).

Flut/Let-males sang part A with a significantly lower maximum frequency during and after the STI than before the STI. In contrast, the maximum frequency of part A did not change before, during and after the STI in placebo-implanted males (Table 1, Fig. 3a). Both treatment groups sang part B with a significantly higher maximum frequency during the STI than before the STI. Furthermore, the maximum frequency of this part tended to remain high after the STI in placebo-implanted males but not in Flut/Let-males (Table 1). Consequently, placebo-implanted males sang part B with a significantly larger frequency bandwidth during and after the STI than before the STI, while frequency bandwidth of part B did not change in Flut/Let-implanted males (Table 1, Fig. 3b).

Maximum frequency and the frequency bandwidth of part $\mathrm{C}$ did not change in response to the STI or Flut/Let-treatment (Table 1).

\section{Song in Fall}

In both treatment groups focal males sang fewer songs during and after the STI than before the experimental challenge (Fig. 2b, Table 2). Males of both treatment groups increased the number of elements in part A (Fig. 4c) and C (Fig. 4d) in response to the experimental challenge while decreasing the maximum frequency of part A (Fig. 4a) and decreasing the frequency bandwidth of part C (Table 2). Males sang part B with a significantly higher maximum frequency in response to the simulated territorial intrusion than during spontaneous song and this did again not significantly differ between placebo and Flut/Let-implanted males (Table 2). However, this effect is not reflected in a higher frequency bandwidth of part $\mathrm{B}$ in fall, in contrast to placeboimplanted males in spring (Fig. 4b, Table 2). Furthermore, changes in the frequency bandwidth of part B occur at a far narrower range in fall than in spring (Figs. $3 \mathrm{~b}$ and $4 \mathrm{~b}$ ). With regard to the effect sizes (Table 2) we suggest to treat the results on frequency measures in fall with caution.

\section{Discussion}

In this study, we explored the role of testosterone (and its estrogenic metabolites) in modulating song characteristics of black redstarts in a spontaneous and a reactive context both during breeding and non-breeding. Territorial males of both treatment groups and in both seasons did change structural song parameters in an aggressive context. In spring, both treatment groups increased the number of elements sung in parts of their song in response to the STI. However, Flut/Let males decreased the maximum acoustic frequency of one song part in response to the STI, while placebo-implanted males kept this acoustic measure constant throughout the challenge. Furthermore, placebo-implanted males sang the atonal part of their song with a broader frequency range. In contrast to Flut/Let males, placebo-implanted males increased signal density by singing shorter songs with shorter pauses between song parts in the STI. In summary, these results provide a good example of the activational role of testosterone not only on song activity in general, but also on the specific singing style depending on the context.

The results of this study indicate that song sung during a territorial encounter is of higher competitive value than song sung in an undisturbed situation and may, therefore, convey information about the motivation or quality of the territory holder. During simulated intrusions in fall, when testosterone levels are naturally low in this species, males of both treatment groups sang similar to Flut/Let-implanted males during breeding. We conclude that these changes in song in response to a simulated territorial intruder were influenced by the Flut/Let treatment and by season: structural changes in song were less pronounced in Flut/Let males and in all males during non-breeding in fall compared to placebo-implanted males in spring.

\section{Song Modulation during Territorial Challenges}

Black redstarts of both treatment groups in spring sang more elements in parts $\mathrm{A}$ and $\mathrm{C}$ and placebo-implanted birds increased the frequency bandwidth of part $\mathrm{B}$ when a simulated rival intruded the territory. Additionally, Flut/Let males decreased the maximum frequency of part $\mathrm{A}$. These structural song parameters have been suggested to be physically challenging in other species (reviewed in [16]). Also, with regard to trilled parts, it has been suggested previously that the production of repeated (trilled) syllables with a high frequency bandwidth is challenging (reviewed in [16]). For example, in swamp sparrows, male age, size, and early developmental conditions correlated with these song characteristics, and can therefore serve as honest signals of male quality $[14,56,5]$. Females of some species prefer songs sung with a high trill rate and broad frequency bandwidth [12,57]. Furthermore, swamp sparrows increase both trill rate and frequency bandwidth in response to simulated territorial intruders [10].

Even though songs of control males were shorter during the STI than before (which might occur counter-intuitive at first, since usually birds increase song output when challenged), this resulted in a higher signal density. Increasing the signal density by changing the song output in an aggressive context seems to be a common strategy among bird species (e.g. [30,58]). In our study on black redstarts, this increase was realized by a shortening of pauses between song parts.

\section{Treatment and Season Affect Song Modulation during Territorial Challenges}

Although all males (regardless of treatment and season) changed their song in the aggressive context, Flut/Let males in spring and all males challenged during non-breeding in fall did so to a lesser extent than placebo males during breeding in spring. The changes that we find to be inhibited by the Flut/Let-treatment in spring (i.e. maximum frequency of part A and frequency bandwidth of part B) are similar to the parameters Cucco and Malacarne (1999, [47]) found to be characteristic for adult males̀ song as opposed to yearling males' song. These parallels in acoustic features that differ between age-groups [47] and males of different hormonal status (our study) deserve further consideration. Yearlings as well as 
males with low testosterone levels might fail to produce challenging acoustic features due to lack of experience. Considering that adult male black redstarts (singing 'mature song') in general have a higher reproductive success than yearlings $[48,49]$, we assume that this mature song is indicating a better quality and our Flut/Let-implanted males failed to produce this 'mature song'. Thus, context-dependent changes in song structure may indeed reveal information about the quality of the producer.

In Flut/Let-implanted males during spring and all males during fall the increase in the number of elements in part $\mathrm{A}$ was associated with a decrease in its maximum frequency. Therefore, Flut/Letmales in spring and all males in fall tended to sing this song part with a lower frequency bandwidth during a challenge than during spontaneous song. This might be interpreted as a failure to increase the number of elements and maintain the frequency at the same time in terms of a performance constraint, or alternatively, that Flut/Let-implanted males invested less into the production of these signals than did placebo-implanted birds in spring. Considering that territorial behaviors other than song were not affected by a Flut/Let-treatment in spring (Apfelbeck et al., under revision) it is likely that motivational differences can not exclusively account for our results.

In addition, in contrast to placebo-implanted males Flut/Let males did not increase the frequency bandwidth of song part $\mathrm{B}$. Part B consists only of a single noisy song element. Noisy elements are characterized as atonal, non-harmonic sounds occupying a range of frequencies (Fig. 1). There are good reasons to assume that such atonal song elements are not produced by the syrinx but by modulating the airflow in the vocal tract (reviewed in [59]). Accordingly, placebo-implanted birds may sing with a higher air pressure and thus louder than Flut/Let-males. As a consequence, a broader range of frequencies is "broadcasted" in placeboimplanted males than in Flut/Let-males. Alternatively, a broader frequency range might be achieved by an increase in beak opening (e.g. [60]). In barn swallows, the song characteristics of a similar harsh or noisy element, the rattle, were correlated with testosterone concentration [30]. Changing the acoustic properties of such elements within limits may be interpreted as a way to increase their signal value as described in the framework of index signals.

Our results obtained in breeding and non-breeding males suggest that some, though not all song response measures in an aggressive context are mediated by testosterone or estradiol. Blocking these hormones particularly affected structural song measures. This may indicate that testosterone represents an underlying mechanism allowing the modification of 'index signals' such as trill rate or frequency measures. Similar results were recently reported for singing mice $[61,62]$ and may thus reflect a general mechanism in vertebrates. In birds, such a modification within limits may be achieved for example by modifying properties of the syrinx, an organ that is sensitive to testosterone and estradiol

\section{References}

1. Searcy WA, Nowicki S (2005) The evolution of animal communication: Reliability and deception in signaling systems. Princeton: Princeton University Press.

2. Gil D, Gahr M (2002) The honesty of bird song: multiple constraints for multiple traits. Trends Ecol Evol 17: 133-141.

3. Garamszegi LZ, Møller AP, Török J, Michl G, Péczely P, et al. (2004) Immune challenge mediates vocal communication in a passerine bird: an experiment. Behav Ecol 15: 148-157.

4. Kipper S, Kiefer S (2010) Age-related changes in bird's singing styles: on fresh tunes and fading voices? Adv Study Behav 41: 77-118.

5. Searcy WA, Peters S, Kipper S, Nowicki S (2010) Female sparrows use song to assess male developmental history. Behav Ecol Sociobiol 64: 1343-1349.

6. Halupka K, Borowiec M (2006) Male whitethroats, Sylvia communis, advertise their future contribution to parental care. Behaviour 143: 1-14.
[63-65], or the beak muscles [60]. In addition, the neuronal coordination of singing might be affected by changes in testosterone levels, too (reviewed in [66]). Studies on male Gambel's white-crowned sparrows (Zonotrichia leucophrys Gambelii) did provide evidence that decreasing or increasing testosterone levels in the brain can affect the nuclei of the song control system within very few days or even hours $[67,68]$. Furthermore, in some species testosterone levels rise during territorial disputes (reviewed in [69], [70] and this increase in testosterone may affect the behavior and persistence of the male during or after the challenge $[71,72]$. However, black redstarts do not show such a short-term increase in testosterone levels during territorial intrusions [51,73]. Thus, any effects of testosterone on song and territorial behavior probably take place as a consequence of the increase in testosterone at the beginning of the breeding season (i.e. an activational effect).

Furthermore, these context-dependent changes in song may be regulated by aromatase activity in the pre-optic area $[40,74]$ or changes in androgen and estrogen sensitivity in the song control nucleus HVC [75] because redstarts show a higher expression of aromatase mRNA in the pre-optic area in spring than in fall, but no seasonal change in HVC size (Apfelbeck et al., under review).

\section{Conclusions}

Our study demonstrates that blocking the actions of testosterone affected both song output and structural song measures of black redstarts during competitive situations during the breeding season, but not outside the breeding season. We conclude that testosterone may affect both the signal parameters indicating the motivation and/or the ability to engage in competitive interactions such as territorial disputes. This might be achieved by effects of testosterone on the neuronal and physiological capabilities to produce certain song elements depending on the behavioral context. This very nicely illustrates that hormones can change the likelihood of a behavior, often in a context-dependent manner [76].

\section{Acknowledgments}

We thank Erwin Nemeth, Henrik Brumm, Gabriel Beckers, Sue-Ann Zollinger and Manfred Gahr for valuable discussions about the study, Alexander Weber for assisting in the field, and two anonymous referees for providing constructive criticisms on earlier versions of the manuscript.

\section{Author Contributions}

Conceived and designed the experiments: BA S. Kiefer KGM WG S. Kipper. Performed the experiments: BA S. Kiefer KGM WG. Analyzed the data: BA S. Kiefer KGM. Contributed reagents/materials/analysis tools: S. Kipper WG. Wrote the paper: BA WG S. Kipper.

7. Searcy WA, Beecher MD (2009) Song as an aggressive signal in songbirds. Anim Behav 78: 1281-1292.

8. Bartsch C, Weiss M, Kipper S (2012) The return of the intruder: Immediate and later effects of different approach distances in a territorial songbird. Ethology 118: 876-884

9. Price JJ, Earnshaw SM, Webster MS (2006) Montezuma oropendolas modify a component of song constrained by body size during vocal contests. Anim Behav 71: 799-807.

10. DuBois AL, Nowicki S, Searcy WA (2009) Swamp sparrows modulate vocal performance in an aggressive context. Biol Lett 5: 163-165.

11. DuBois AL, Nowicki S, Searcy WA (2011) Discrimination of vocal performance by male swamp sparrows. Behav Ecol Sociobiol 65: 717-726.

12. Draganoiu TI, Nagle L, Kreutzer M (2002) Directional female preference for an exaggerated male trait in canary (Serinus canaria) song. Proc R Soc B 269: 25252531. 
13. Draganoiu T, Pasteau M, Nagle L (2006) Do different elements of black redstart song have different threat values? J Ornithol 147: 158-159.

14. Illes AE, Hall ML, Vehrencamp SL (2006) Vocal performance influences male receiver response in the banded wren. Proc R Soc B 273: 1907-1912.

15. Voigt C, Leitner S (2008) Seasonality in song behaviour revisited: Seasonal and annual variants and invariants in the song of the domesticated canary (Serinus canaria). Horm Behav 54: 373-378.

16. Podos J, Lahti DC, Moseley DL (2009) Vocal performance and sensorimotor learning in songbirds. Adv Study Behav 40: 159-195.

17. Vallet EM, Beme L, Kreutzer M (1997) Two-note syllables in canary songs elicit high levels of sexual display. Anim Behav 55: 291-297.

18. Botero CA, Rossman RJ, Caro LM, Stenzler LM, Lovette IJ, et al. (2009) Syllable type consistency is related to age, social status and reproductive success in the tropical mockingbird. Anim Behav 77: 701-706.

19. Hurd PL, Enquist M (2005) A strategic taxonomy of biological communication. Anim Behav 70: 1155-1170.

20. Bee MA, Perrill SA (1996) Responses to conspecific advertisement calls in the green frog (Rana clamitans) and their role in male-male communication. Behaviour 133: 283-301.

21. Weiss M, Kiefer S, Kipper S (2012) Buzzwords in females' ears? The use of buzz songs in the communication of nightingales (Luscinia megarhynchos). PLoS ONE 7(9): e45057. Available: http://www.plosone.org/article/info:doi/10.1371/ journal.pone.0045057. Accessed 16 November 2012.

22. Adkins-Regan E (2005) Hormones and animal social behavior. Princeton: Princeton University Press.

23. Harding CF (2004) Hormonal modulation of singing: hormonal modulation of the songbird brain and singing behavior. Ann NY Acad Sci 1016: 524-539.

24. Wingfield JC, Moore IT, Goymann W, Wacker DW, Sperry TS (2006) Contexts and ethology of vertebrate aggression: implications for the evolution of hormonebehavior interactions. In: RJ Nelson, editor. Biology of Aggression. New York: Oxford University Press, 179-210.

25. Silverin B (1980) Effects of long-acting testosterone treatment on freeliving pied flycatchers, Ficedula hypoleuca, during the breeding period. Anim Behav 28: $906-$ 912.

26. Ketterson ED, Nolan V Jr, Wolf L, Ziegenfus C. (1992) Testosterone and avian life histories: effects of experimentally elevated testosterone on behavior and correlates of fitness in the dark-eyed Junco (funco hyemalis). Am Nat 140: 980999.

27. Hau M, Wikelski M, Soma KK, Wingfield JC (2000) Testosterone and yearround territorial aggression in a tropical bird. Gen Comp Endocrinol 117: 20 33.

28. Boseret G, Carere C, Ball GF, Balthazart J (2006) Social context affects testosterone-induced singing and the volume of song control nuclei in male canaries (Serinus canaria). J Neurobiol 66 1044-1060.

29. Ritschard M, Laucht S, Dale J, Brumm H (2011) Enhanced testosterone levels affect singing motivation but not song structure and amplitude in Bengalese finches. Physiol Behav 102: 30-35.

30. Galeotti P, Saino N, Sacchi R, Møller AP (1997) Song correlates with social context, testosterone and body condition in male barn swallows. Anim Behav 53: $687-700$.

31. Cynx J, Bean NJ, Rossman I (2005) Testosterone implants alter the frequency range of zebra finch songs. Horm Behav 47: 446-451.

32. Kunc HP, Foerster K, Vermeirssen ELM, Kempenaers B (2006) Experimentally elevated plasma testosterone levels do not influence singing behaviour of male blue tits (Parus caeruleus) during the early breeding season. Ethology 112: 984 992.

33. Weatherhead PJ, Metz KJ, Bennett GF, Irwin RE (1993) Parasite faunas, testosterone and secondary sexual traits in male red-winged blackbirds. Behav Ecol Sociobiol 33: 13-23.

34. Fusani L (2008) Endocrinology in field studies: Problems and solutions for the experimental design. Gen Comp Endocrinol 157: 249-253.

35. Edler R, Goymann W, Schwabl I, Friedl TW (2011) Experimentally elevated testosterone levels enhance courtship behaviour and territoriality but depress acquired immune response in red bishops Euplectes orix. Ibis 153: 46-58.

36. Van Duyse E, Pinxten R, Snoeijs T, Eens M (2005) Simultaneous treatment with an aromatase inhibitor and an anti-androgen decreases the likelihood of dawn song in free-living male great tits, Parus major. Horm Behav 48: 243-251.

37. Smith GT, Brenowitz EA, Wingfield JC (1997) Seasonal changes in testosterone, neural attributes of song control nuclei, and song structure in wild songbirds. J. Neurosci. 17: 6001-6010.

38. Leitner S, Voigt C, Garcia-Segura LM, van't Hof T, Gahr M (2001) Seasonal activation and inactivation of song motor memories in wild canaries is not reflected in neuroanatomical changes of forebrain song areas. Horm Behav 40: 160-168.

39. DeWolfe BB, Kaska DD, Peyton LJ (1974) Prominent variations in the songs of Gambel's white-crowned sparrows. Bird Banding 45: 224-252.

40. Riters LV, Eens M, Pinxten R, Duffy DL, Balthazart J, et al. (2000) Seasonal changes in courtship song and the medial preoptic area in male European starlings (Sturnus vulgaris). Horm Behav 38: 250-261.

41. Landys MM, Goymann W, Schwabl I, Trapschuh M, Slagsvold T (2010) Impact of season and social challenge on testosterone and corticosterone levels in a yearround territorial bird. Horm Behav 58: 317-325.

42. Logan CA, Wingfield JC (1990) Autumnal territorial aggression is independent of plasma testosterone in mockingbirds. Horm Behav 24: 568-581.
43. Schwabl H (1992) Winter and breeding territorial behaviour and levels of reproductive hormones of migratory European robins. Ornis Scand 23: 271276.

44. Wingfield JC (1994) Control of territorial aggression in a changing environment. Psychoneuroendocrinol 19: 709-721.

45. Logan CA, Fulk KR (1984) Differential responding to spring and fall song in mockingbirds (Mimus polyglottos). J Comp Psychol 98: 3-9.

46. Schlinger BA, London SE (2006) Neurosteroids and the songbird model system. J Exp Zool 305A: 743-748.

47. Cucco M, Malacarne G (1999) Is the song of black redstart males an honest signal of status? Condor 101: 689-694.

48. Landmann A, Kollinsky C (1995) Age and plumage related territory differences in male black redstarts: The (non)-adaptive significance of delayed plumage maturation. Ethol Ecol Evol 7: 147-167.

49. Landmann A (1996) Der Hausrotschwanz: Vom Fels zum Wolkenkratzer; Evolutionsbiologie eines Gebirgsvogels. Wiesbaden: AULA-Verlag.

50. Weggler M. (2000) Reproductive consequences of autumnal singing in black redstarts (Phoenicurus ochruros). The Auk: 65-73.

51. Apfelbeck B, Goymann W (2011) Ignoring the challenge? Male black redstarts (Phoenicurus ochruros) do not increase testosterone levels during territorial conflicts but they do so in response to gonadotropin-releasing hormone. Proc R Soc Biol B 278: $3233-3242$

52. Balthazart J (1997) Steroid control and sexual differentiation of brain aromatase. J Steroid Biochem Mol Biol 61: 323-339.

53. Hau M (2007) Regulation of male traits by testosterone: implications for the evolution of vertebrate life histories. Bioessays 29: 133-144.

54. Cheshenko K, Pakdel F, Segner H, Kah O, Eggen RI (2008) Interference of endocrine disrupting chemicals with aromatase CYP19 expression or activity, and consequences for reproduction of teleost fish. Gen Comp Endocrinol 155: 31-62.

55. R Development Core Team (2009) R: A language and environment for statistical computing. Vienna: R Foundation for Statistical Computing.

56. Ballentine B (2009) The ability to perform physically challenging songs predicts age and size in male swamp sparrows, Melospiza georgiana. Anim Behav 77: 973978.

57. Ballentine B, Hyman J, Nowicki S (2004) Vocal performance influences female response to male bird song: An experimental test. Behav Ecol 15: 163-168.

58. Beckett MD, Ritchinson G (2010) Effects of breeding stage and behavioral context on singing behavior of male indigo buntings. Wilson J Ornithol 122: 655-665.

59. Riede T, Goller F (2010) Peripheral mechanisms for vocal production in birds: differences and similarities to human speech and singing. Brain Lang 115: 6980

60. Hoese WJ, Podos J, Boetticher NC, Nowicki S (2000) Vocal tract function in birdsong production: experimental manipulation of beak movements. J Exp Biol 203: 1845-1855.

61. Pasch B, George AS, Campbell P, Phelps SM (2011) Androgen-dependent male vocal performance influences female preference in Neotropical singing mice. Anim Behav 82: 177-183.

62. Pasch B, George AS, Hamlin HJ, Guillette LJ, Phelps SM (2011) Androgens modulate song effort and aggression in Neotropical singing mice. Horm Behav 59: $90-97$

63. Veney SL, Wade J (2004) Steroid receptors in the adult zebra finch syrinx: a sex difference in androgen receptor mRNA, minimal expression of estrogen receptor alpha and aromatase. Gen Comp Endocrinol 136: 192-199.

64. Veney SL, Wade J (2005) Post-hatching syrinx development in the zebra finch: an analysis of androgen receptor, aromatase, estrogen receptor alpha and estrogen receptor beta mRNAs. J Comp Physiol A Sens Neural Behav Physiol 191: 97-104.

65. Wade J, Buhlman L (2000) Lateralization and effects of adult androgen in a sexually dimorphic neuromuscular system controlling song in zebra finches. J Comp Neurol 426: 154-164.

66. Balthazart J, Charlier TD, Barker JM, Yamamura T, Ball GF (2010) Sex steroidinduced neuroplasticity and behavioral activation in birds. Eur J Neurosci 32: 2116-2132.

67. Thompson GK, Bentley GE, Brenowitz EA (2007) Rapid seasonal-like regression of the adult avian song control system. Proc Natl Acad Sci U S A 104: $15520-15525$.

68. Thompson CK, Brenowitz EA (2010) Neuroprotective effects of testosterone in a naturally occurring model of neurodegeneration in the adult avian song control system. J Comp Neurol 23: 4760-4770.

69. Goymann W, Landys MM, Wingfield JC (2007) Distinguishing seasonal androgen responses from male-male androgen responsiveness - Revisiting the challenge hypothesis. Horm Behav 51: 463-476.

70. Goymann W (2009) Social modulation of androgens in male birds. Gen Comp Endocrin 163: 149-157.

71. Wingfield JC (1994) Regulation of territorial behavior in the sedentary song sparrow, Melospiza melodia morphna. Horm Beh 28: 1-15.

72. Oyegbile TO, Marler CA (2005) Winning fights elevates testosterone levels in California mice and enhances future ability to win fights. Horm Behav 48: 259267.

73. Apfelbeck B, Stegherr J, Goymann W (2011) Simulating winning in the wild The behavioral and hormonal response of black redstarts to single and repeated territorial challenges of high and low intensity. Horm Behav 60: 565-571. 
74. Riters LV, Ball GF (1999) Lesions to the medial preoptic area affect singing in the male European starling (Sturnus vulgaris). Horm Behav 36: 276-286.

75. Gahr M, Metzdorf R (1997) Distribution and dynamics in the expression of androgen and estrogen receptors in vocal control systems of songbirds. Brain Res Bull 44: 509-517.
76. Monaghan EP, Glickman SE (1992) Hormones and aggressive behavior. In: Becker JB, Breedlove SM, Crews D, editors. Behavioral endocrinology. Cambridge, MA: MIT Press. 261-285. 